\title{
Didactic Games - Fundamental Teaching Activity in Preschool Education
}

\author{
Nicoleta Ramona Ciobanu* \\ Assistant Professor, PhD, University of Oradea, Faculty of Humanistic and Social Sciences, Universităţii Street, \\ no.1, 410087, Oradea, Bihor County, Romania \\ *Corresponding Author: Nicoleta Ramona Ciobanu, Assistant Professor, PhD, University of Oradea, \\ Faculty of Humanistic and Social Sciences, Universităţii Street, no.1, 410087, Oradea, Bihor County, \\ Romania
}

\begin{abstract}
The present paper highlights the contribution of the didactic game, which is a specific type of activity through which the didactic framework consolidates, specifies and even verifies the students' knowledge, enriches the knowledge sphere, valorises and trains their creative capacities. The paper aims at identifying strategies, methods, and modern means of carrying out activities in the kindergarten, which stimulate the interest of preschoolers, to discover new methods of active involvement of preschoolers. Language is one of the most important skills that a preschool child acquires, and it is also a key element in acquiring good education in school and later in the university environment.
\end{abstract}

Keywords: Didactic Game; Activity; Education; Quality of Teaching; Formative Values.

\section{INTRODUCTION}

The present paper highlights the contribution of the didactic game, which is a specific type of activity through which the didactic framework consolidates, specifies and even verifies the students' knowledge, enriches the knowledge sphere, valorises and trains their creative capacities. Language is one of the most important skills that a preschool child acquires, and it is also a key element in acquiring good education in school and later in the university environment.

Language development includes the following: phonetic, lexical, grammatical, and semantic evolution. It is already known that pre-school children are excellent conversational partners - not just asking a lot of questions, but they like to tell them a lot. This feature greatly helps parents and educators in vocabulary development and communication skills in children.

A recent study conducted by Raikes H., Pan B.A., Luze G., Tamis-LeMonda, C.S., Brooks-Gunn, J., Constantine, J., Tarullo, L.B., Raikes, H.A., \& Rodriguez, E.T. (2006) evoked the effects of reading by mothers in the first three years of life of children. Parents are encouraged to read stories to their children to foster the development of language and cognitive abilities. Mothers and children participated in an Early Head Start evaluation study, a federal program that helps 62,000 low-income families in 7,000 communities nationwide. Early Head Start offers services at home or in service centres to improve child development and parenting skills. More than 1,100 women with 14, 24 and 36 months of age were interviewed. Some of them participated in the Early Head Start program and others were part of the control group. Mothers were asked about the frequency with which they read stories to children. Questions about family resources and issues have also been raised. Experienced researchers made standard measurements of vocabulary and cognitive abilities of children. Nearly half of mothers reported reading their child daily at the age of 14, and the number of mothers grew as the elderly child advanced. The frequency they were reading was associated with the child's cognitive and speech results at the same age and at a later age. Generally, the more mothers read their children, the more vocabulary and cognitive skills of the children would be gained so that at the age of 3 (when children start to be interested in pre-reading activities), the children to whom they were read daily during the first two years of their life had significantly higher cognitive and language scores.

The most important result was that mother reading practice influenced the language of the child by 
creating a mutual effect of "snowball" and thus proving that early exposure to reading develops speech skills, which in turn led to developing reading and vocabulary. In other words, babies exposed to reading at an early age began to speak earlier and showed interest in books, which brought about an increasing interest in reading, thus developing their cognitive and vocabulary skills. The game is a set of actions and operations that, along with the relaxation, good mood and joy, pursue objectives of intellectual, technical, moral, physical training. of the child. Incorporated in the didactic activity, the game element imparts to it a more vivid and attractive character, it brings variety and a good functional disposition, of joy and joy, of entertainment and of relaxation, which prevents the appearance of monotony and boredom, of fatigue. Restoring a balance in the activity of preschoolers, the game strengthens their intellectual and physical energies, generating a secondary but stimulating motivation, constituting an indispensable presence in the rhythm of the school work.

Therefore, when the game is used in the educational process, it acquires significant psychopedagogical functions, ensuring the active participation of children in activities, increasing the interest in knowing about their content. Integrated activities imply a certain degree of integration between the different areas of knowledge and between different approaches, as well as the use of a common language, allowing for conceptual and methodological exchanges. Integrated activity also involves the transfer of methods from one discipline to another, transfer with different degrees of involvement, completion.

Integration can also be manifested by correlating information specific to some areas, overcoming barriers between them through the exchange of methods, knowledge, and means. The correlation of knowledge specific to different categories of activities contributes substantially to the formation and development of thinking flexibility, to the development of children's ability to apply knowledge in practice - one discipline helps the other to be better mastered, transferring knowledge from one domain to another. An important place in the child's preparation for school is the language education, which has a major influence both on the development of all psychological processes and on the personality of the children. As the first step of education, pre-school education is conceived in a systemic vision, having a structure, conducting a process and generating a specific product. Early education refers to childhood early childhood education (from birth to 8 years) and gives it specific conditions for full development, respecting individual and age development. Early education starts from the idea that small ages are the basis of personality, and for the educational success of the child it is necessary to train all the factors with which it interacts, starting with family members, educators, community. If a child does not receive enough care, love, attention in the first years of his life, he may be left with a learning deficit that may endanger his further development, along the school path and in society. The first two years of life of the child are those in which the sense of self appears and the identity of the child is built. In this sense, it is particularly important for him to see for the first time, how he thinks, how he thinks that others should work with him. Early education takes into account some very important principles in developing the child's personality:

- Every child is unique, has specific and particular needs.

- Education is continuous; it begins in the first moments of life and lasts as long as this.

- Every act of care is an educational approach, and the active interaction with the adult is defining.

- child development is dependent on the opportunities offered by the daily routine

- Learning small children is done through explorations and experiences in game situations.

When the toddler when first entered kindergarten, he faces a new experience. The well-known psychologist Jean Piaget has made an important contribution to educational theories. The four stages mentioned by him are:

- Sensorimotor development stage (from birth to 2 years) - knowledge of the world is based on physical interactions and experiences.

- Preoperative stage (2-7 years) - the intelligence of the child increases with the use of symbols, memory and intelligence develops in close connection with language and its use, thinking is irreversible and egocentric. 
- The Operational Concrete Stage (7-12 years) - the child's intelligence increases, demonstrating logical and systematic manipulation of symbols in close connection with concrete objects, thinking is operational, reversible, and less egocentric.

- Formal Operations Status (over 12 years) - intelligence is felt through the use of logic of symbols, in close connection with abstract concepts, thinking is psycho-behavioural, fundamental whose quality will greatly influence the level of adaptation and integration of the child in the later stages of his evolution and development.

Pre-school age is a period of discovery, the child learns, everything through the game, that there is an exciting world, and wants to get involved to know it. The game is an essential activity, at first it is solitary, then parallel to the game of others and characterized by impulsivity, discontinuity. At this age, the child does not go to the others, he is even afraid of them, and has moments when he has a profound sense of insecurity. But, along the way, the child learns to trust him as they form some behaviour, and the game is his daily activity. Through the game he meets his need for movement, curiosity, and even faces his fears. The rich content of the activities become accessible through language and transforms by acquiring skills, skills and beneficial skills in later stages of evolution as an individual. The most elaborate form of play in pre-school education is the didactic game that has a high formative value at this age. The didactic game as a basic activity in the development of the preschool speech plays a decisive role, while realizing one of the most important pre-school education requirements, namely the correct acquisition of the Romanian language, as this condition determines the development of thinking and other psychological and intellectual processes. A child who manages to correct his pronunciation mistakes, who will be encouraged to look for solutions to vocabulary enrichment, will become more confident in his own power and will participate with interest in activities.

\section{GAME FunCTIONS}

Psychologists have shown that play plays a very important role in the child's evolution. Multiple classifications also involve the idea of game functions. The game has main and secondary features. The main function of the game is to allow the individual to realize and outline his personality. Thus, the play after Claparède would be "a substitute for serious work". Everyone is required to use the game for two reasons:

- Because he is incapable of performing serious work due to insufficient development.

- Because of circumstances that are opposed to performing a serious activity that satisfies that desire. So the obstacles can be of two kinds: external (inappropriate environment) or internal (moral censorship). The most common functions in the literature are:

- COGNITIVE FUNCTION is a function of knowledge. The game is the favourite activity of the child, in the kindergarten he is encouraged to play always. At the basis of the organization of the educational-educational process, it is up to this natural need to play.

- ADAPTIVE FUNCTION is manifested by the assimilation of physical and social reality. Through the game, the preschool translates impressively into the physical and social environment, thus managing to cope more easily with the demands of reality and the surrounding world.

- FORMATIVE FUNCTION is very important and has been highlighted by pedagogues like FROBEL and has been developed by modern pedagogy. It is accomplished through exercise game, which is what drives the child's mental activity. In the face of the real problems the game requires, children exercise their ability to analyze the problem-solving possibilities so that the game continues. The child's creativity and creative imagination is stimulated by the game. Through creative imagination children can face real-life situations.

- INFORMATIONAL FUNCTION is the function in which, through the game, the child assimilates information, notions that are necessary for integration into the real world.

- THE FUNCTION OF SOCIALIZATION is marked by the constantly high tendency of children to accommodate each other, but also to assimilate their relationships with those around him. This feature is especially present in rule play and involves accepting rules and 
rules outside, but once won, it is becoming a good gained by the child. Children have the opportunity to explore, experiment, learn new things. The child's tendency to defend individuality, along with the need to integrate into society, is an important aspect of socialization through play.

- PSYCHIC RELEVANCE FUNCTION refers to the fact that the child lives and transposes feelings, feelings, and fears. These intense experiences of the child are remarkable through the game, the way in which they choose their material resources, the subject, and the game partners. Educators along with parents may notice any disturbances that may arise in the child's development. Elements that can influence the character of the child are: the level of intellectual development, the life experience of the child, the adult life model. The child takes over the context and the living environment in which he lives.

- EDUCATIONAL FUNCTION refers to the fact that the game contributes both to the improvement of cognitive functions and to the involvement of the internal motivation, as well as to the development of some skills. We refer here to those tasks of the game that concern the child's physiological and psychological development, developing them with qualities and techniques of intellectual work, and the children manage to integrate easily into the new social environment. As secondary functions of the didactic game we may note the balancing function and the therapeutic function.

\section{Classification OF GameS}

Game is the basic activity in the kindergarten. Through the game, as I have already said, the child tries to get to know the world around and it is considered to be pre-learning activity. By acting on the objects and beings around, the child knows the surrounding world, satisfies his need for movement and understanding, acquires confidence in his own forces, and defines himself as a personality. The game must offer a sense of satisfaction and delight, as it is always accompanied by pleasure, motivation and satisfaction. Thus, children can remain involved in the game that pleases them, trying to "mistake", "laugh," "to fool," "to speak loudly", "to interact with the children they feel good about ".

The game is intertwined with wonder and curiosity; children are always attracted by the novelty of everything new. All these cultivate their need for knowledge, stimulating their exploration efforts. The cultivation of curiosity gives a playful character to the situations in which children are involved, forces them to solve problems, invent, try, ask, observe, explore. The game also involves freedom of movement, but it is more common in motion games. Children can choose their own partners, play as much as they want, shares their roles, change the rules themselves when they want. Classification of games has preoccupied many preschool pedagogues. "By ordering their classification according to the function they fulfil, Edgar Claparède classifies the games into two major categories: games that perform general functions and games that perform special functions." (Tomşa, 2005). Piaget orders the games according to the evolutionary criteria and groups them into the following categories:

- Exercise games

- Symbolic games

- Rules Games

- Construction games

\section{The Didactic Game Contribution to the InTEllectual DeVelopment of The Child}

The role of the game in the intellectual development of the preschool involves both acquiring new knowledge and developing the imagination. Imagination is at play, both for the child and for the adult, the environment conducive to its manifestation and development.

"The involuntary memorization during the game is also only a passage for voluntary memorization (the rules of the game). Generalization and classification as didactic game requirements involve thinking operations and are easier to achieve when they are motivated by the requirements game. Fundamental in the development of the child is the acquisition of language, which is closely related to thinking and at the same time, fulfils a regulatory and social function."(Voiculescu, 2001). The game, 
especially the didactic, aims to fix fundamental lexical terms, to correct and improve the pronunciation, to acquire certain nouns that refer to objects or phenomena from the near environment. The educator must be with the child, follow him, and guide him discreetly throughout his progress. It is the main source of stimulating the child, always correcting it, widening its knowledge. The educator also encourages his imagination, causes the child to express his impressions, opinions and wishes. Verbalizing, the educator encourages him to develop, but also respects his individuality.

\section{The Contribution of the Game to the Moral DeVelopment of The Child}

At pre-school age, the child cannot distinguish between good and bad and is not able to choose the reference values. The child must be formed by virtue of positive values, and the negative ones must be completely removed. This is actually the essence of moral education. Until the entrance to the kindergarten, but also to school, the family is the primary environment for the moral education of the child. The teacher has an important role to play in the inspiration of moral education and can play through the game the desiderata of the pre-school moral education, referring to a series of general objectives related to the social area - the attitude, the affective area and the cognitive area.

Exercise games, role-playing games and rules games provide a broad context in which the child can operate with the main moral values, applying rules and rules. Pre-school purchases should be evaluated by the adult at behaviour level.

The game is a good school for relationships between children, as they are accepted, valued and desirable in this context as those who manifest themselves correctly and who resist their negative emotions. It provides an extrinsic motivation for children to form some behavioural skills, some discipline rules, to exercise their determination, perseverance, self-mastery, honesty, competitiveness, fair-play conduct. Stimulating through play is the way to use playful fiction as a framework and educational medium.

The task of the educator towards the moral development of the child is not easy at all. She must teach the child to overcome the conflict between personal desire and the rule of the game. It is the best exercise for the development of self-regulation, because by internalising the external regulation made by the educator will become the child's own. Later on, the stimulation by the educator will no longer be necessary because the preschool will have some models previously presented by her, and on the other hand the child will adjust her actions according to the answers received from her playmates. The sympathy, approval, satisfaction of the acceptance in the game as a partner of others is the best incentive to continue in this direction.

\section{The Formative Values of the toys in the Preschool Game and their Role to CHILD'S DEVELOPMENT}

The toy is very important for the little baby. It determines the character of the game and the emotional experiences of the child. The formative valences of the toy are multiple. Through this, the thinking operations are developed: analysis, synthesis, comparison, generalization (puzzle games, demountable toys, doll house, toy kitchen). The toy develops creativity, imagination (changing dolls, accessory machines, thematic games: farm, fire-fighters, shop, etc.). Managing some toys develops children's ability to perceive form and spatial relationships: puzzle, set of ascending glasses, illustrated cubes, swings, etc.). Children develop a lot of language by talking and always communicating with their favourite toys (musical toys, story books, interactive dolls, etc). The toy will be the most important object of the little baby, being invaluable and having a very important role in its life. Through it, the character of the adult of tomorrow, this gives the child confidence and self-confidence.

The term "didactic", associated with the game, emphasizes the instructive-educational aspect of the activity, which becomes an integral part of it, and is concretized through a certain level of knowledge, common and mental actions that it requires. Regardless of the age of the child, the didactic game offers an informative and formative aspect to the educational process.

Teaching plays a special role in the development of pre-school children's speech, as this form of play trains the child into stimulating and practicing speech in the proposed direction within each game without realizing this effort. Didactic games are more effective and more attractive than other activities in the kindergarten because all the children in the group participate with the same effort of thought and expression. 


\section{REFERENCES}

[1] Bârsan, N. (1995). Didactic games specific to language development and oral communication of major preschoolers. Editura Didactică şi Pedagogică, Bucharest.

[2] Chateau, J., \& Răutu, D. (1970). Child and play. Editura Didactică şi Pedagogică. Jarvis, P. (Ed.). (2006). The theory and practice of teaching. Routledge.

[3] Claparède, E. (1911). Experimental Pedagogy and the Psychology of the Child. Longmans, Green and Company.

[4] Lindqvist, G. (1996). The aesthetics of play. A didactic study of play and culture in preschools. Early Years, 17(1), 6-11.

[5] Neagu, M. R. (2011). The didactic game-way of access to the child's soul. Bacău: Romimed.

[6] Piaget, J., \& Inhelder, B. (2008). The psychology of the child. Basic books.

[7] Raikes, Helen \& Luze, Gayle \& Brooks-Gunn, Jeanne \& Raikes, H \& Alexander Pan, Barbara \& S. Tamis-LeMonda, Catherine \& Constantine, Jill \& Banks Tarullo, Louisa \& T. Rodriguez, Eileen. (2006). Mother-Child Bookreading in Low-Income Families: Correlates and Outcomes During the First Three Years of Life. Child Development, vol. 77, no. 4.

[8] Rosenfield, L. W., Hayes, L. S., \& Frentz, T. S. (1976). The communicative experience. Allyn \& Bacon.

[9] Tomşa, G., Chelaru, M., Ilade, C., Iurea, C., Mălureanu, F., \& Ştefănescu, C. (2005). Preschool and school psychopedagogy. Editat Revista Învățământul Preşcolar, Bucureşti.

[10] Voiculescu, E. (2001). Pre-school pedagogy. Aramis, Bucharest.

Citation: Nicoleta Ramona Ciobanu. "Didactic Games - Fundamental Teaching Activity in Preschool Education" International Journal of Humanities Social Sciences and Education (IJHSSE), vol 5, no. 11, 2018, pp. 32-37. doi: http://dx.doi.org/10.20431/2349-0381.051104.

Copyright: (C) 2018 Authors. This is an open-access article distributed under the terms of the Creative Commons Attribution License, which permits unrestricted use, distribution, and reproduction in any medium, provided the original author and source are credited. 